\title{
BMJ Open Associations between adolescent experiences, parent experiences and HbA1c: results following two surveys based on the Norwegian Childhood Diabetes Registry (NCDR)
}

\author{
Hilde Hestad Iversen (D , ${ }^{1}$ Oyvind Bjertnaes (D) , ${ }^{1}$ Torild Skrivarhaug ${ }^{2,3}$
}

To cite: Iversen $\mathrm{HH}$, Bjertnaes 0 , Skrivarhaug T. Associations between adolescent experiences, parent experiences and HbA1c: results following two surveys based on the Norwegian Childhood Diabetes Registry (NCDR). BMJ Open 2019;9:e032201. doi:10.1136/ bmjopen-2019-032201

- Prepublication history and additional material for this paper are available online. To view these files, please visit the journal online (http://dx.doi. org/10.1136/bmjopen-2019032201).

Received 11 June 2019 Revised 18 September 2019 Accepted 04 October 2019

Check for updates

(c) Author(s) (or their employer(s)) 2019. Re-use permitted under CC BY-NC. No commercial re-use. See rights and permissions. Published by BMJ.

${ }^{1}$ Division of Health Services, Norwegian Institute of Public Health, Oslo, Norway

${ }^{2}$ Division of Paediatric and Adolescent Medicine, The Norwegian Childhood Diabetes Registry, Oslo University Hospital, Oslo, Norway

${ }^{3}$ Institute of Clinical Medicine, University of Oslo, Oslo, Norway

Correspondence to Dr Hilde Hestad Iversen; hilde.hestad.iversen@fhi.no

\section{ABSTRACT}

Objective The aim of the current study was to determine the association between the experiences of adolescents and their parents with paediatric diabetes care at hospital outpatient departments and the association between these experiences and the Hemoglobin $\mathrm{A} 1 \mathrm{c}(\mathrm{HbA} 1 \mathrm{c})$ levels of adolescents.

Design Cross-sectional survey.

Setting Paediatric diabetes care at hospital outpatient departments in Norway.

Participants Parents of all outpatients registered in the Norwegian Childhood Diabetes Registry and patients in the same registry aged 12-17 years.

Intervention 1399 parents participated in a national pilot survey and 335 patients aged 12-17 years from the four largest paediatric outpatient departments in Norway responded in another pilot study. 181 paired parental and patient questionnaires were analysed.

Main outcome measures The correlations between single items, indicator scores and overall scores were explored, as was that between indicator scores and $\mathrm{HbA1C}$ levels.

Results There was a moderate but significant correlation between the responses of the patients and parents. For 40 of the 42 associations the correlations were significant, ranging from 0.16 to 0.42 . A weak but significant negative correlation was found between the indicator scores of parents and the $\mathrm{HbA} 1 \mathrm{c}$ levels of the adolescents. The strongest correlations were between $\mathrm{HbA} 1 \mathrm{c}$ level and nurse contact and organisation, both with a correlation coefficient of $0.21(p<0.01)$. There was no significant correlation between $\mathrm{HbA} 1 \mathrm{c}$ level and patient indicator scores.

Conclusions These results highlight the need to obtain information from both parents and adolescents, and indicate that the views of adolescents are not always mirrored by their parents. Three of the seven parent experience indicators were significantly related to the $\mathrm{HbA1c}$ levels of adolescents, but replication in future research with larger sample sizes is warranted.

\section{INTRODUCTION}

Norway has one of the highest incidences of childhood-onset type 1 diabetes in the world,
Strengths and limitations of this study

- The study used validated instruments whose survey content and response scales were adapted for the specific patient/parent and age groups included.

- Both parents and adolescents experiences were explored, and the results can provide guidance concerning the most appropriate care to provide at outpatient clinics.

- The surveys were performed by an independent third party that was not involved in providing healthcare.

- While the parent survey was nationwide, the adolescent survey was restricted to four clinics and the results should be replicated in larger surveys.

- Another limitation is that our study was based on responses being received from both parents and adolescents, which may have introduced selection bias.

and $0.6 \%(\mathrm{n}=28000)$ of the total population has type 1 diabetes. ${ }^{1}$ Type 1 diabetes usually develops in childhood or early adolescence, and parents therefore play an important role in the day-to-day management of the disease. This responsibility places considerable demands on parents, and family involvement is a crucial component of optimal diabetes management. $^{2}$

Adolescents experience challenges to adherence that are intrinsic to their developmental stage and demands for peer normality. ${ }^{3}$ Diabetes may become a daily struggle against undesirable blood glucose levels and risk complications, hormonal changes can lead to insulin resistance and there are several other factors underlying poor glycaemic control in this phase of life. ${ }^{4}$

Norwegian children attend follow-up appointments with a paediatrician and a diabetes nurse at their local paediatric outpatient department in hospitals approximately four times yearly. Dieticians and psychologists 
can also be consulted if requested. Given the importance of the parental role in the healthcare decisions and daily follow-up of adolescents, the interactions between the adolescent and parent plus those with the healthcare provider are an important component of the outpatient visit.

There is a growing recognition of the importance of assessing the experiences of patients with healthcare when attempting to provide patient-centred health services. Reviews have found that better patient experiences and satisfaction are associated with higher levels of adherence to recommended prevention and treatment interventions as well as better clinical outcomes. ${ }^{5-7}$ An adult population-based survey of patients with type 2 diabetes found that strategies that increased patient satisfaction also contributed to improving the clinical outcomes. ${ }^{8}$ Another study found that the parent ratings of the quality of outpatient diabetes care were negatively correlated with the mean Hemoglobin A1c (HbA1c) levels of their children. In the same study adolescents aged $>13$ years who reported a higher quality of care had lower HbAlc levels. ${ }^{9}$ However, other studies have not found significant correlations between the satisfaction of young peoples with diabetes care and their HbA1c levels. ${ }^{10-12}$

Parents or caregivers are usually asked to respond on behalf of children younger than a certain age. The views of children and adolescents have largely been ignored in large-scale patient-experience surveys, despite evidence that children may be willing to respond from the age of 8 years and that their healthcare priorities diverge from those of their parents from the age of 12 years. ${ }^{13-15} \mathrm{~A}$ cross-sectional analysis of national survey data in England showed that including inpatients aged 8-15 years in a patient-experience survey was both feasible and enhanced the information obtained from the responses of parents alone. $^{13}$

The results from previous studies show that there are discrepancies between assessments of healthcare services by children and their parents or caregivers. ${ }^{13}{ }^{16-20} \mathrm{~A}$ review found that young people aged 16-24 years consistently report worse healthcare experiences compared with older adults. ${ }^{18}$ Another study found a strong correlation between the quality of diabetes care as perceived by parents and adolescents, but differences in the importance that the two populations placed on different aspects of care. ${ }^{9}$ The level of agreement is generally better between parents and their chronically sick children than between parents and their healthy children. ${ }^{21}$

Information about potential differences in perceptions could be useful for providers when delivering outpatient care, and when trying to balance the needs and expectations of adolescents and their parents. Also, such findings can provide guidance when measuring and monitoring patient and parent experiences with outpatient care for the purpose of quality improvement. The aim of the present study was to determine the association between the experiences of adolescents and parents with paediatric diabetes care at hospital outpatient departments, and the association between these experiences and the HbA1c level of the adolescents. To our knowledge, only two previous studies have simultaneously assessed the associations between parent experiences, adolescent experiences and clinical outcomes for this patient group,,${ }^{912}$ and none of them were performed in Norway. Based on those previous studies, we hypothesised that there would be a correlation between the perceptions of parents and the adolescents about the quality of outpatient care, but no correlation with the HbAlc level.

\section{METHODS \\ Data}

Responses from adolescents were collected in a pilot study that included all patients at the four largest outpatient departments in Norway who were aged 12-17 years, had type 1 diabetes and were registered in the Norwegian Childhood Diabetes Registry (NCDR) $(n=685)$. The purpose of the pilot study was to determine the data quality, validity and internal consistency reliability of the newly developed instrument. A report published in 2018 documents the development of the instrument and the data collection method. ${ }^{22}$ The sample was contacted by post in April 2017. The request included a letter with information about the survey, a printed version of the questionnaire, a prepaid return envelope and also an option to answer electronically. Non-responders were sent up to two postal reminders. The national parent experience survey has been described elsewhere ${ }^{23}{ }^{24}$ and here we include 181 parents that were matched with the adolescent survey. Unique patient identification numbers were used to match parent responses with that of their children.

All paediatric departments report the results of annual standardised examinations to the NCDR. Background data were transferred from the NCDR to the Norwegian Institute of Public Health (NIPH) after data collection was completed, but for a few patients data on HbAlc and the number of consultations were not complete at the time of transfer.

\section{Measures}

Two new measures were developed and tested in accordance with the standard methodology of the national userexperience survey programme in Norway ${ }^{23}{ }^{24}$ : the Parent Experiences of Diabetes Care Questionnaire (PEQ-DC) and the Adolescent Patient Experiences of Diabetes Care Questionnaire (APEQ-DC) ${ }^{23}$ The questionnaires were designed to be applied in surveys of parents of children and adolescents with type 1 diabetes of all ages and of adolescents with type 1 diabetes aged $12-17$ years visiting paediatric outpatient departments in Norway, and are included in online supplementary additional file 1 and online supplementary additional file 2.

We asked about experiences at the paediatric outpatient clinic that the child visited for follow-up appointments. Five-point scales with response options that ranged from 
'not at all' (1) to 'a very large extent' (5) were used for most items relating to the experience of care. Smiley faces were used to illustrate the response options in the APEQDC. Many items also included a 'not applicable/don't know' option. An open-ended question on the last page was asked for further comments.

The PEQ-DC and APEQ-DC had similar (but not identical) contents. The results obtained in the development process showed that certain themes or questions were not relevant for both groups. The process highlighted the importance of ensuring that the patient questionnaire was as short as possible while also comprising age-appropriate items. The psychometric testing of the PEQ-DC identified six indicators: consultation, organisation, equipment, nurse contact, doctor contact and outcome. Five indicators were identified for the APEQ-DC: consultation, information on food/exercise, nurse contact, doctor contact and outcome.

The HbAlc level is a measure of long-term blood glucose levels and reflects the average level over the preceding 4-12 weeks, weighted towards the most recent 4 weeks. Data were obtained from the NCDR and reported as percentages and in millimoles per mole $(\mathrm{mmol} / \mathrm{mol})$.

\section{Statistical analysis}

Overall scores for each respondent were calculated by summing the scores for all of the indicators and dividing by their total number.

The Mann-Whitney U test was used to test the differences in scores between patients who reached the recommended $<7.5 \%$ treatment goal, and patients who did not reach the recommended treatment goal. Corresponding analyses were conducted for the parents, based on the HbAlc value of their children. The Mann-Whitney U test was also used to compare the self-reported experiences of the parents and patients for eight single items.

The relationship between the patient and parent experiences at the outpatient clinic was tested by calculating Spearman's rank correlation coefficients for indicator scores, the overall scores and single items. Multivariate linear regression analyses were used to further assess the associations between the patient and parent experiences, controlling for age, gender and HbAlc level.

The indicator scores and overall scores were also correlated with the HbA1c level analysed as a continuous variable. Correlations were assessed using Spearman's rank correlation. Multivariate linear regression analyses were used to assess the associations, controlling for age and gender.

All statistical analyses were conducted using SPSS V.23.0.

\section{Approval}

Both surveys were approved by the Data Protection Authority at Oslo University Hospital. Registration in the NCDR is based on a signed informed consent from the child (older than 12 years) and/or the child's parents. The consent form informs the patient and/or the parents that consent may result in requests to answer questionnaires on patient and parent experiences of diabetes care. Returning the questionnaire constituted consent in the survey.

\section{Patient and public involvement}

The survey was about patients and parents experiences with experiences with healthcare. Patients and parents were included in the development process of the instrument, to secure that the questionnaire included the most important topics for patients and parents.

\section{RESULTS}

One thousand three hundred and ninety-nine (55.4\%) parents responded to the questionnaire, while questionnaire responses were received from 335 (53.6\%) adolescent patients. We were able to match 181 parents with the adolescent survey, and the overall coverage rate in this study was $26.4 \%$. The characteristics of the 181 included adolescents and their parents are presented in table 1 . Fifty-four per cent of the adolescents were boys, and their mean age was 14.7 years (table 1 ). The mean age when diagnosed with type 1 diabetes was 9.4 years, and the mean HbA1c level at the last registration in the NCDR was $8.2 \%(66.1 \mathrm{mmol} / \mathrm{mol})$. The mean age of the parents was 46.0 years and $78.8 \%$ were female (table 1 ), while $70.4 \%$ had a university or college education.

Table 2 lists the indicator scores and item scores for both adolescents and parents. The adolescent indicators had scores ranging from 57.2 (for information on food/exercise) to 87.3 (for doctor contact), and the overall score was 78.5. The parent indicator scores ranged between 60.6 (for equipment) and 79.9 (for nurse contact), and the overall score was 72.9. Analyses showed that for four of the single items the adolescent scores were significantly higher than the parent scores (results not shown). Table 2 also shows the indicator scores and item scores for patients who achieved the recommended $<7.5 \%$ treatment goal and patients who did not achieve the $<7.5 \%$ treatment goal. Corresponding results are shown for parents, based on the HbAlc values of their children. No significant differences in scores were found for patients who achieved the $<7.5 \%$ treatment goal and patients who did not achieve the treatment goal. Parents of children who reached the treatment goal had significantly higher scores on one of the single items (nurses knowledgeable).

Table 3 presents the coefficients for the correlations between the indicator scores of the adolescents and parents. All of the correlations were statistically significant except the adolescent score for nurse contact and the parent score for doctor contact, and the adolescent score for doctor contact and the parent score for equipment. The significant correlation coefficients ranged from 0.16 to 0.42 . The strongest correlations were between the adolescent score for the consultation indicator and the parent score for the outcome indicator $(\mathrm{r}=0.42, \mathrm{p}<0.001)$ and the overall score indicator 
Table 1 Background characteristics of the adolescents $(n=181)$ and the parents $(n=181)$

\begin{tabular}{|c|c|}
\hline Characteristic & $\% /$ mean \\
\hline \multicolumn{2}{|l|}{ Adolescents } \\
\hline \multicolumn{2}{|l|}{ Sex, \% } \\
\hline Male $(n=98)$ & 54.1 \\
\hline Female $(n=83)$ & 45.9 \\
\hline Mean age, years $(n=181)$ & 14.7 \\
\hline $\begin{array}{l}\text { Mean age when diagnosed with diabetes, } \\
\text { years }(n=181)\end{array}$ & 9.4 \\
\hline Mean diabetes duration, years $(n=181)$ & 5.4 \\
\hline Mean HbA1c level, \% (n=165) & 8.2 \\
\hline \multicolumn{2}{|l|}{$\begin{array}{l}\text { Number of consultations during previous } \\
\text { year (mean: 6.2), \% }\end{array}$} \\
\hline $1-3(n=40)$ & 24.4 \\
\hline $4-6(n=48)$ & 29.3 \\
\hline $7-9(n=57)$ & 34.8 \\
\hline $10-21(n=19)$ & 11.6 \\
\hline \multicolumn{2}{|l|}{ General condition today, \% } \\
\hline Very poor $(n=1)$ & 0.6 \\
\hline Fairly poor (n=3) & 1.7 \\
\hline Neither poor nor good $(n=31)$ & 17.2 \\
\hline Fairly good ( $n=89)$ & 49.4 \\
\hline Very good $(n=56)$ & 31.1 \\
\hline \multicolumn{2}{|l|}{ Norwegian \% } \\
\hline Yes $(n=169)$ & 93.4 \\
\hline No $(n=12)$ & 6.6 \\
\hline \multicolumn{2}{|l|}{ Parents } \\
\hline \multicolumn{2}{|l|}{ Sex, \% } \\
\hline Male $(n=38)$ & 21.2 \\
\hline Female $(n=141)$ & 78.8 \\
\hline Mean age, years $(n=179)$ & 46.0 \\
\hline \multicolumn{2}{|l|}{ Education, \% } \\
\hline Primary school $(n=3)$ & 1.7 \\
\hline Secondary school $(n=50)$ & 27.9 \\
\hline $\begin{array}{l}\text { University or college ( } 0-4 \text { years) } \\
(n=54)\end{array}$ & 30.2 \\
\hline University or college (>4 years) $(n=72)$ & 40.2 \\
\hline \multicolumn{2}{|l|}{ Living with the child's other parent, \% } \\
\hline Yes $(n=140)$ & 78.7 \\
\hline No $(n=38)$ & 21.3 \\
\hline
\end{tabular}

Number of consultations during previous year (mean: 4.3), \%

\begin{tabular}{lr} 
None $(n=3)$ & 1.7 \\
$1(n=7)$ & 4.0 \\
$2(n=21)$ & 11.9 \\
$3(n=58)$ & 32.8 \\
4 or more $(n=88)$ & 49.7 \\
\hline
\end{tabular}

Data are \%/mean. $(\mathrm{r}=0.41, \mathrm{p}<0.001)$, respectively. The correlation coefficient between the adolescent score for the overall score indicator and the parent score for the outcome indicator was also $0.41(p<0.001)$. The coefficient for the correlation between the parent and adolescent overall scores was $0.41(\mathrm{p}<0.001)$.

Table 4 indicates that all correlations between individual questions with identical wordings in the two surveys were significant. The strongest correlation was for the questions pertaining to meeting the same doctor $(r=0.50$, $\mathrm{p}<0.001)$ and if the patient and parent were well received $(\mathrm{r}=0.32, \mathrm{p}<0.001)$.

No significant correlations were found between the adolescent indicators and their HbAlc level (table 5). Three of the seven parent indicators were significantly correlated with the HbAlc level. The strongest correlation was found between HbA1c level and nurse contact and organisation, both with a correlation coefficient of $0.21(\mathrm{p}<0.01)$.

We also tested if the difference in overall mean scores for the parent and the adolescent had an influence on the HbAlc level, but the results did not support this association (results not shown here).

\section{DISCUSSION}

This study found high average ratings from both adolescents and parents, but with the evaluations from parents being somewhat more critical. The parent experiences did not accurately represent the views of the patient, as demonstrated by weak-to-moderate correlations. Three of seven parent experience indicators were correlated with the HbA1c level, but this was not the case for the adolescent experiences.

Most previous studies have found discrepancies between assessments of healthcare services by children and their parents or caregivers, ${ }^{1316-20}$ which is in line with our findings. However, one of the very few studies related to diabetes outpatient care found a very strong correlation between patient and parent assessments. ${ }^{9}$ There are several possible reasons for explaining the lack of convergence, but we believe the questionnaires used and the measurement approach might be the main reasons. That previous study initially used a general patient-experience questionnaire for adult patients, then adjusted it to an adolescent diabetes version and a parent version ${ }^{9}$ but without performing further testing and validation. ${ }^{25}$ Although this was not stated explicitly, it appears that the two surveys of how patients and parents perceived the care received were carried out simultaneously. If so, the surveys were not independent, and the parents and adolescents might have completed the questionnaires jointly. ${ }^{25}$ This raises questions about the validity of both questionnaires, the measurements made and the estimated correlations.

Unlike the results obtained in previous surveys, ${ }^{131619}$ the current study found that the average indicator scores for adolescents were higher than the average indicator scores for their parents. These previous studies had varying 
Table 2 Indicator scores and single item scores of adolescents and parents in the total sample and for adolescents and parents where the patients have achieved/not achieved the treatment goal

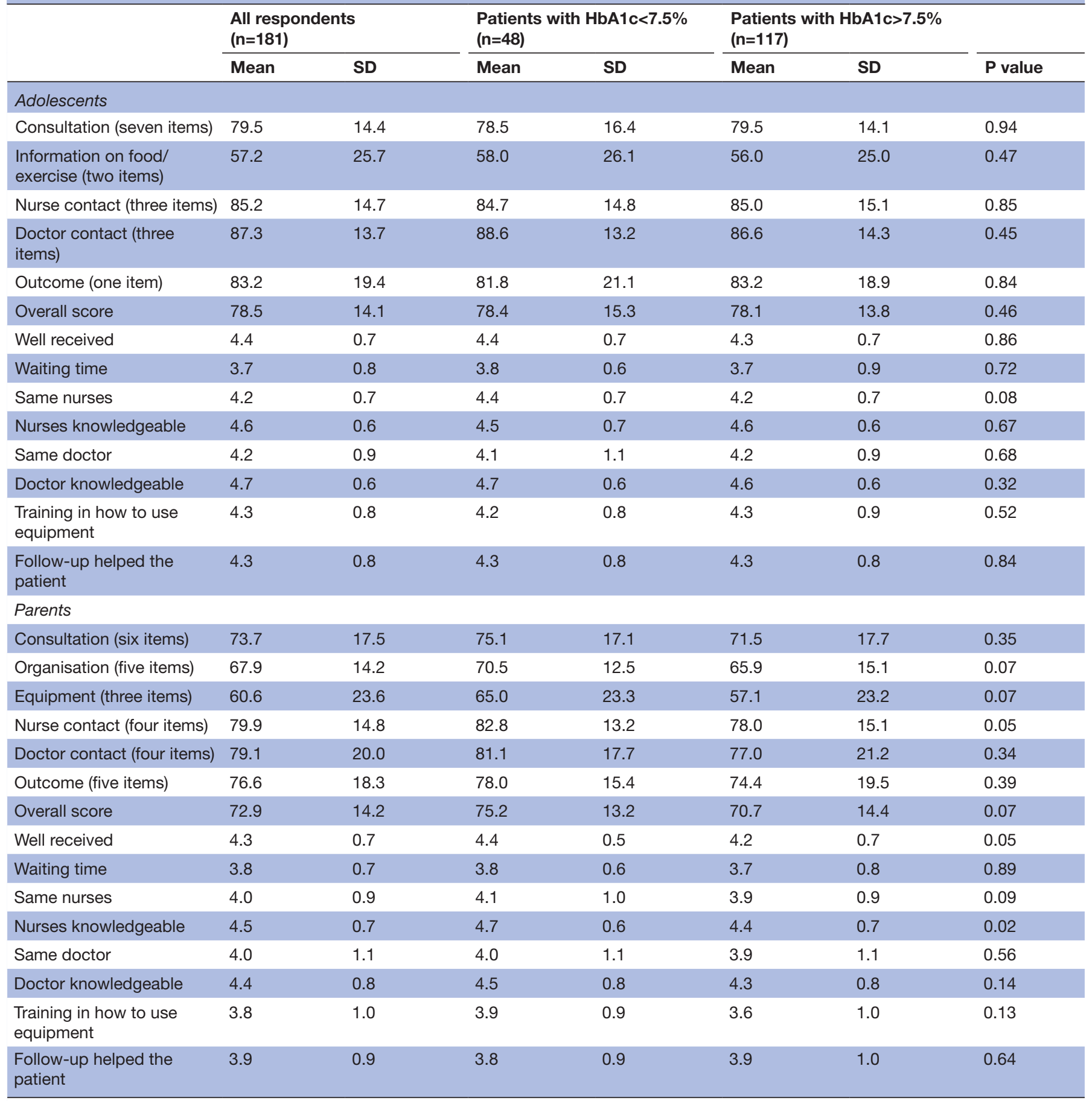

All indicators were scored from 0 to 100 , where 100 was the best possible experience. Individual items were scored from 1 to 5 , where 5 is the best possible experience. Differences in scores were tested by Mann-Whitney $\mathrm{U}$ test.

contexts and methodologies, but none of them based their comparisons on questionnaires that were developed and validated specifically for each group. Furthermore, our finding is in accordance with the general patientsatisfaction literature indicating that proxies are more critical than patients. ${ }^{26-31}$ The indicator score for adolescents in our study was lowest for information on food/ exercise, suggesting that more time should be spent on providing adolescents with such information. These findings are in accordance with previous research highlighting communication and information as an area for improvement. ${ }^{9131920}$ Adolescents gave the highest ratings for the doctor contact indicator, while the parents scored equipment the lowest and nurse contact the highest.

No significant associations between the adolescent indicators and $\mathrm{HbA1c}$ level were found, in line with previous studies. ${ }^{10-12}$ However, three of the seven parent indicators were correlated significantly with the adolescent 


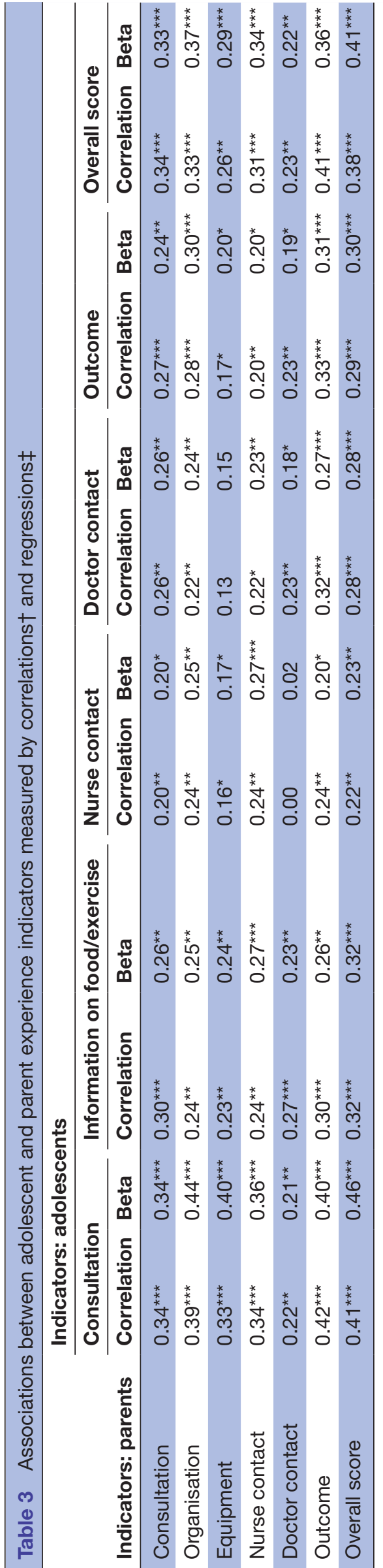

Table 4 Associations between adolescent and parent experiences for single items measured by correlations $\uparrow$ and regressionsł

\begin{tabular}{|c|c|c|}
\hline Item & Correlation & Beta \\
\hline Well received & $0.32^{\star \star \star}$ & $0.28^{\star * *}$ \\
\hline Waiting time & $0.22^{\star \star}$ & $0.21^{\star \star}$ \\
\hline Same nurses & $0.25^{\star \star}$ & $0.22^{\star *}$ \\
\hline Nurses knowledgeable & $0.26^{\star \star \star}$ & $0.29^{\star \star \star}$ \\
\hline Same doctor & $0.50^{\star * *}$ & $0.46^{\star \star *}$ \\
\hline Doctor knowledgeable & $0.29^{\star \star \star}$ & $0.22^{\star *}$ \\
\hline Training in how to use equipment & $0.24^{\star \star}$ & $0.41^{\star \star *}$ \\
\hline Follow-up helped the child & $0.30^{\star \star \star}$ & $0.27^{\star \star}$ \\
\hline
\end{tabular}

${ }^{\star *} \mathrm{P}<0.01,{ }^{* \star *} \mathrm{P}<0.001$.

†Spearman's rank correlation coefficients.

$\ddagger$ Standardised regression coefficients adjusted for patient age, gender and $\mathrm{HbA} 1 \mathrm{c}$ level.

HbAlc levels. The results from the current study also showed that parents of children who reached the recommended $<7.5 \%$ treatment goal reported better experiences related to the nurses' knowledge. Previous studies and reviews have found associations between patient experiences or satisfaction and adherence to recommended prevention and treatment processes and clinical outcomes. ${ }^{5-9}$ In this setting it therefore seems that parents have a closer connection to clinical quality than

Table 5 Associations between adolescent and parent experiences and $\mathrm{HbA} 1 \mathrm{c}$ level measured by correlations $\dagger$ and regressionsł

\begin{tabular}{lll}
\hline & HbA1c & \\
\cline { 2 - 3 } Indicator/item & Correlation & Beta \\
\hline Adolescents & & \\
Consultation & 0.01 & 0.07 \\
\hline Information on food/exercise & -0.01 & 0.02 \\
\hline Nurse contact & -0.02 & 0.03 \\
\hline Doctor contact & -0.05 & -0.03 \\
\hline Outcome & -0.03 & 0.00 \\
\hline Overall score & -0.05 & 0.02 \\
\hline Parents & & \\
Consultation & -0.12 & -0.11 \\
\hline Organisation & $-0.21^{\star *}$ & -0.14 \\
\hline Equipment & -0.15 & -0.07 \\
\hline Nurse contact & $-0.21^{\star *}$ & $-0.19^{\star}$ \\
\hline Doctor contact & -0.13 & $-0.18^{\star}$ \\
\hline Outcome & -0.15 & -0.15 \\
\hline Overall score & $-0.20^{\star *}$ & $-0.17^{\star}$ \\
\hline
\end{tabular}

${ }^{*} \mathrm{P}<0.05,{ }^{* *} \mathrm{P}<0.01$.

†Spearman's rank correlation coefficients.

$\ddagger$ Standardised regression coefficients adjusted for patient age and gender. 
do the adolescents themselves. The implication is that interventions to improve parent experiences also might improve clinical outcomes but more research conducted with larger sample sizes is needed to conclude on this observed association.

The assumption that adults can answer for children has traditionally gone unchallenged. The views of children and adolescents have largely been ignored in large-scale surveys, and parents or carers are often asked to respond on their behalf. There is a need to develop methods that allow young people to provide feedback on the quality of healthcare that they themselves consider relevant. The two instruments applied in this study were developed in a rigorous manner. Considering the important role played by parents in diabetes treatment regimes, studies exploring the relationship between experiences and adherence must take into account the perspectives and needs of both parent and adolescent. Understanding differences and similarities between these two groups can provide guidance concerning the most appropriate care to provide at outpatient clinics.

This study was subject to some limitations. Data on nonrespondents were not available, and we were not able to compare the characteristics of the current sample with the characteristics of those who did not respond to the survey. However, results from the national parent survey were published in a recent article and showed similar background characteristics for the current sample and the total national sample of 1399 respondents. While the parent survey was nationwide, the adolescent survey was restricted to four clinics. Only 181 paired parental and patient responses were analysed, an overall coverage rate of $26.4 \%$. This raises questions about the generalisability of the findings, and the results should be replicated in larger surveys. Also, our study was based on responses being received from both parents and adolescents, which may have introduced selection bias.

\section{CONCLUSIONS}

All but one of the correlations between the indicator scores of the parents and adolescents were statistically significant, but the agreements between the reported experiences were all only weak or moderate. The results highlight the need to collect information from both parents and adolescents, and confirm that the views of adolescents are not always mirrored by their parents. Three of seven parent experience indicators were significantly related to the adolescent HbAlc level. However, more research is needed to further explore the associations between parent experiences and the HbAlc level. Understanding the correspondence between the viewpoints of parents and adolescents is potentially useful for informing interventions aimed at improving the healthcare provided at paediatric outpatient departments. ${ }^{23}$

Acknowledgements We thank Inger Opedal Paulsrud, Olaf Holmboe, Johanne Kjøllesdal and Nam Pham from the Knowledge Centre at the NIPH for their help in developing and conducting the surveys, including performing administrative and technical tasks for the data collection. We further thank Ann Kristin Drivvoll from the NCDR for extracting data from the registry.

Contributors TS initiated the study. HHI planned the study in consultation with $\mathrm{OB}$ and $\mathrm{TS}$. HHI performed the statistical analyses with $\mathrm{OB}$ and TS, and drafted the manuscript. OB and TS participated in the planning process, critically revised the manuscript draft and approved the final version of the manuscript. HHI was the project manager for the two surveys. All authors read and approved the final manuscript.

Funding This work was supported by the Knowledge Centre at the NIPH, the NCDR and 'Lillian and Werner Næss legat'. The NCDR is funded by the South-Eastern Norway Regional Health Authority.

Competing interests None declared.

Patient consent for publication Not required.

Provenance and peer review Not commissioned; externally peer reviewed.

Data availability statement No data are available.

Open access This is an open access article distributed in accordance with the Creative Commons Attribution Non Commercial (CC BY-NC 4.0) license, which permits others to distribute, remix, adapt, build upon this work non-commercially, and license their derivative works on different terms, provided the original work is properly cited, appropriate credit is given, any changes made indicated, and the use is non-commercial. See: http://creativecommons.org/licenses/by-nc/4.0/.

ORCID iDs

Hilde Hestad Iversen http://orcid.org/0000-0002-6191-416X

Oyvind Bjertnaes http://orcid.org/0000-0002-4261-5455

\section{REFERENCES}

1 Strøm H, Selmer R, Birkeland KI, et al. No increase in new users of blood glucose-lowering drugs in Norway 2006-2011: a nationwide prescription database study. BMC Public Health 2014;14:520.

2 Laffel LMB, Vangsness L, Connell A, et al. Impact of ambulatory, family-focused teamwork intervention on glycemic control in youth with type 1 diabetes. J Pediatr 2003;142:409-16.

3 Borus JS, Laffel L. Adherence challenges in the management of type 1 diabetes in adolescents: prevention and intervention. Curr Opin Pediatr 2010;22:405-11.

4 Datye KA, Moore DJ, Russell WE, et al. A review of adolescent adherence in type 1 diabetes and the untapped potential of diabetes providers to improve outcomes. Curr Diab Rep 2015;15:51.

5 Anhang Price R, Elliott MN, Zaslavsky AM, et al. Examining the role of patient experience surveys in measuring health care quality. Med Care Res Rev 2014;71:522-54.

6 Doyle C, Lennox L, Bell D. A systematic review of evidence on the links between patient experience and clinical safety and effectiveness. BMJ Open 2013;3:e001570.

7 Ofman JJ, Badamgarav E, Henning JM, et al. Does disease management improve clinical and economic outcomes in patients with chronic diseases? A systematic review. Am J Med 2004;117:182-92.

8 Alazri MH, Neal RD. The association between satisfaction with services provided in primary care and outcomes in type 2 diabetes mellitus. Diabet Med 2003;20:486-90.

9 Hanberger L, Ludvigsson J, Nordfeldt S. Quality of care from the patient's perspective in pediatric diabetes care. Diabetes Res Clin Pract 2006;72:197-205.

10 de Wit M, Delemarre-van de Waal HA, Bokma JA, et al. Monitoring and discussing health-related quality of life in adolescents with type 1 diabetes improve psychosocial well-being: a randomized controlled trial. Diabetes Care 2008;31:1521-6.

11 Gray S, Cheetham T, McConachie H, et al. A longitudinal, observational study examining the relationships of patient satisfaction with services and mental well-being to their clinical course in young people with type 1 diabetes mellitus during transition from child to adult health services. Diabet Med 2018;35:1216-22.

12 Koves IH, Boucher A, Ismail D, et al. Satisfaction of care in a tertiary level diabetes clinic: correlations with diabetes knowledge, clinical outcome and health-related quality of life. J Paediatr Child Health 2008;44:432-7

13 Hargreaves DS, Sizmur S, Pitchforth J, et al. Children and young people's versus parents' responses in an English national inpatient survey. Arch Dis Child 2018;103:486-91. 
14 Ambresin A-E, Bennett K, Patton GC, et al. Assessment of youthfriendly health care: a systematic review of indicators drawn from young people's perspectives. J Adolesc Health 2013;52:670-81.

15 Santelli JS, Rosenfeld WD, DuRant RH, et al. Guidelines for adolescent health research: a position paper of the Society for adolescent medicine. J Adolesc Health 1995;17:270-6.

16 Chesney M, Lindeke L, Johnson L, et al. Comparison of child and parent satisfaction ratings of ambulatory pediatric subspecialty care. J Pediatr Health Care 2005;19:221-9.

17 Sawyer SM, Ambresin A-E, Bennett KE, et al. A measurement framework for quality health care for adolescents in hospital. $J$ Adolesc Health 2014;55:484-90.

18 Hargreaves DS, Viner RM. Children's and young people's experience of the National health service in England: a review of national surveys 2001-2011. Arch Dis Child 2012;97:661-6.

19 Byczkowski TL, Kollar LM, Britto MT. Family experiences with outpatient care: do adolescents and parents have the same perceptions? J Adolesc Health 2010;47:92-8.

20 Hopwood B, Tallett A. Little voice: giving young patients a say. Nurs Times 2011;107:18-20.

21 Eiser C, Morse R. Can parents rate their child's health-related quality of life? Results of a systematic review. Qual Life Res 2001;10:347-57.

22 Iversen $\mathrm{HH}$, Helland Y, Skrivarhaug T. Development of a method for measuring parent and patient experiences of outpatient care for children with type 1 diabetes. Oslo: The Norwegian Institute of Public Health, PasOpp-report 37, 2018: 1890-1565.

23 Iversen $\mathrm{HH}$, Helland $\mathrm{Y}$, Bjertnaes $\mathrm{O}$, et al. Parent experiences of diabetes care questionnaire (PEQ-DC): reliability and validity following a national survey in Norway. BMC Health Serv Res 2018;18:774.

24 Bjertnaes O, Iversen $\mathrm{HH}$, Skrivarhaug T. A randomized comparison of three data collection models for the measurement of parent experiences with diabetes outpatient care. BMC Med Res Methodol 2018;18:95.

25 Hanberger L. Quality of Care in Children and Adolescents with Type 1 Diabetes: Patients' and Healthcare Professionals' Perspectives. Linköping: Linköping University Electronic Press, 2010.

26 Bjertnaes O. Patient-Reported experiences with hospitals: comparison of proxy and patient scores using propensity-score matching. Int J Qual Health Care 2014;26:34-40.

27 Elliott MN, Beckett MK, Chong K, et al. How do proxy responses and proxy-assisted responses differ from what Medicare beneficiaries might have reported about their health care? Health Serv Res 2008;43:833-48.

28 Epstein AM, Hall JA, Tognetti J, et al. Using proxies to evaluate quality of life. can they provide valid information about patients health status and satisfaction with medical care? Med Care 1989;27:S91-8.

29 O'Malley AJ, Zaslavsky AM, Elliott MN, et al. Case-Mix adjustment of

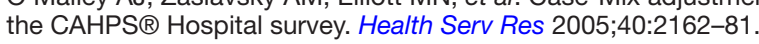

30 Strasser S, Schweikhart S. Welch GE 2nd, Burge JC. Satisfaction with medical care. It's easier to please patients than their family members and friends. J Health Care Mark 1995;15:34-44.

31 Walker $\mathrm{AH}$, Restuccia JD. Obtaining information on patient satisfaction with hospital care: mail versus telephone. Health Serv Res 1984;19:291-306. 